\title{
GGE Biplot Analysis for Stability in Diverse Maturity Groups of Rice (Oryza sativa L.) Advanced Lines
}

\author{
Sreedhar Siddi1\O, D. Anil² and N. Lingaiah ${ }^{3}$
}

${ }^{1}$ Rice Breeding Scheme, Agricultural Research Station, Kunaram, Professor Jayashankar Telangana State Agricultural University, Telangana State (505 174), India

${ }^{2}$ Rice Agronomy Scheme, Agricultural Research Station, Kunaram, Professor Jayashankar Telangana State Agricultural University, Telangana State (505 174), India

${ }^{3}$ Dept. of Genetics and Plant breeding, Agricultural College, Warangal, Professor Jayashankar Telangana State Agricultural University, Hyderabad, Telangana State (506 006), India

Open Access

Corresponding $\$ siddu.35@gmail.com

0000-0002-0890-9169

ABSTRACT

$\mathrm{T}$

The experiment was carried out under three seasons with 15 genotypes at Agricultural Research Station, Kunaram, Telangana state, India during rabi season (December to April) 2014-15 (E1), kharif season (July to November) 2015 (E2) and rabi season (December to April) 2015-16 (E3). The objective of the study was to assess the stability and adaptability of 15 rice genotypes of the various maturity groups over three seasons. The GGE biplot tool of these 15 rice genotypes of various maturity durations expressed a significant genotype, environment and $\mathrm{G} \times \mathrm{E}$ interaction for yield and days to $50 \%$ flowering. Genotype and environment interaction effect was responsible for the greatest part of the variation, followed by genotypes and environment effects for grain yield. Days to $50 \%$ flowering of genotypes was highly affected by environments followed by genotypes, and genotype and environment interaction. It also detected that rabi season 2014-15 (E1) was identified as the best suited season for the potential expression of the grain yield, while kharif season 2015 (E2) was the right season for the expression of reduced days to 50\% flowering. Further, the what-won-where model indicated that short duration rice genotype G14 (KNM 1690) and medium duration genotype G9 (KNM 1632) in the environments rabi season 2014-15 (E1) and kharif season 2015 (E2), respectively and the early line G11 (KNM 1684) in the environment rabi season 2015-16 (E3) were the winning genotypes and suitable for their respective environments for grain yield. G7 (KNM 1616) was the vertex early genotype and closer to the ideal genotype expressed high yield and stability for all the environments. G13 (KNM 1689) and G14 (KNM 1690) were found to be stable for earliness across all the seasons and could be utilized for the development of early duration varieties. The rice genotype, G15 (BPT 5204) was found to be stable for lateness for all the seasons.

KEYWORDS: G×E interaction, GGE Biplot, polygon, rice, stability, yield

Citation (VANCOUVER): Siddi et al., GGE Biplot Analysis for Stability in Diverse Maturity Groups of Rice (Oryza sativa L.) Advanced Lines. International Journal of Bio-resource and Stress Management, 2022; 13(1), 114-121. HTTPS://DOI.ORG/10.23910/1.2022.2597.

Copyright: (C) 2022 Siddi et al. This is an open access article that permits unrestricted use, distribution and reproduction in any medium after the author(s) and source are credited.

Data Availability Statement: Legal restrictions are imposed on the public sharing of raw data. However, authors have full right to transfer or share the data in raw form upon request subject to either meeting the conditions of the original consents and the original research study. Further, access of data needs to meet whether the user complies with the ethical and legal obligations as data controllers to allow for secondary use of the data outside of the original study.

Conflict of interests: The authors have declared that no conflict of interest exists.

RECEIVED on $09^{\text {th }}$ August 2021 


\section{INTRODUCTION}

$\mathrm{B}$ reeding rice varieties with genotype by environment interaction studies play an important role in exercising stable varieties for yield and its contributing traits to improve rice productivity. Plant breeders conduct multienvironment trials (MET) primarily to identify the superior cultivars for a target region and secondarily to determine if the target region can be subdivided into different mega environments (Yan et al., 2000; Crossa et al., 2002). Most breeding programs face complex mega-environments with unpredictable genotype-environment interaction and genotype evaluation based on mean performance and stability has been a perennial problem and challenge (Yan and Kang, 2003). Hence, genotype-environment interaction has been a research focus among the breeders and geneticists which would help to get the information on the adaptability and stability performance and may complement the selection process and recommendation of a genotype for a target environment (Ebdon and Gauch, 2002; Gauch, 2006; Ahmadi et al., 2012; Jeberson et al., 2017). Breeders must therefore use tools to efficiently and accurately measure the response of the lines in multiple test environments (Yan et al., 2007). There are several biometric models proposed to analyze the GEI and explore adaptability and stability. However, multiplicative models that look at the response of genotypes to specific environments or to different environments have more accurate criteria to analyze this phenomenon in different crops (Goncalves et al., 2020). Various statistical models such as AMMI (Gauch, 2006) and GGE biplot models (Yan et al., 2000) are widely used across the seasons to assess their stability and to quantify the effect of genotype $\mathrm{x}$ environment $(\mathrm{GxE})$ interaction on the yield of genotypes (Balakrishnan et al., 2016; Rasul et al., 2017).

Wider adaptability and stability are the prime consideration in formulating effective breeding programs and selecting varieties (Dewi et al., 2014; Worku et al., 2016). The sustainability of rice production depends on the development of new rice cultivars with high yields and stable performance across diverse environments (Akter et al., 2014). It is therefore essential to apply new approaches to increase rice yield in already cultivated areas (Khush, 2005).

Rice has been widely consumed as an essential food for human beings and grown around the world. Over half of the world's population constantly include rice in their diet (Rao et al., 2016; Nili et al., 2017; Sharifi et al., 2017; Poli et al., 2018; Suman et al., 2021) and Asian countries produce nearly $80 \%$ of rice in the world. Among rice growing countries in the world, India has the largest area under rice crop of about 44.1 million hectares with a production of 165.3 million tons; however, its productivity per unit area is low i.e $3.78 \mathrm{t} \mathrm{ha}^{-1}$ (Kesh et al., 2021). Due to escalating population, declining arable land and climate change, demands for higher productivity have become a critical issue in all over the world (Oladosu et al., 2017). Earliness is an important agronomic trait, has the advantage of varieties to suit various cropping situations, especially where the water supply is a limited period of time (Bueno and Lafarge, 2017). It also helps in the escape of crops from various pests and disease incidence and reduces crop loss leads to enhancing rice productivity with profitability and input use efficiency. Even though more than 1000 rice varieties have been released in India, most of the varieties were not accepted due to inconsistent performance in diverse environments. For these reasons, the present study was aimed with objectives to evaluate rice genotypes with varying yield levels and maturity durations for the stability and adaptability in a selected set of rice advanced lines across growing seasons by using GGE biplot analysis.

\section{MATERIALS AND METHODS}

$\mathrm{T}$ he experiment was carried out under three seasons with 15 genotypes during rabi season (December to April) 2014-15 (E1), kharif season (July to November) 2015 (E2) and rabi season (December to April) 2015-16 (E3) at Agricultural Research Station, Kunaram. The details of the experimental material and environments are presented in Table 1.

The farm is geographically situated at $18.6^{\circ} \mathrm{N}$ Latitude, $79^{\circ} \mathrm{E}$ Longitude and an elevation of $231 \mathrm{~m}$ AMSL. The soil is silty loam with $p \mathrm{H} 7.43$ and $\mathrm{EC} 0.26 \mathrm{dS} \mathrm{m}$. $^{-1}$ Based on the imperative trait i.e days to $50 \%$ flowering which was recorded in kharif season 2015 (E2), the genotypes included in the present study were classified into different maturity groups. The experiment was carried out using a randomized complete block design with two replications in three environments. Grain yield was recorded at the time of maturity with $13 \%$ grain moisture and then plot yield in $\mathrm{kg}$ plot $^{-1}$ was converted to $\mathrm{kg} \mathrm{ha}^{-1}$. Days to $50 \%$ flowering were recorded on the day $50 \%$ of plants flowering in an experimental plot. Trial in each season was conducted as one environment for the multi-environment analysis. Data obtained from each season was analyzed separately by running a single analysis of variance and thereafter data from all the three seasons was pooled for analysis of variance to perform the combined analysis of advanced lines across the seasons to test the presence of significant genotype, environment and genotype-environment variation. In general, yield and days to 50\% flowering are complex traits, dependent on several contributing characters and highly influenced by genetics as well as environmental factors. Thus, there is a need to identify the high-yielding stable genotypes in various maturity groups of rice suitable for a wide range of environments. Analysis 
Table 1: Genotype code and designation of diverse maturity group of rice genotypes for three seasons

\begin{tabular}{lccccc}
\hline S1. No. & Genotype code & Designation & Maturity group & $\begin{array}{c}\text { Environment } \\
\text { code }\end{array}$ & Environment \\
\hline 1. & G1 & KNM 1590 & Early & E1 & Rabi season 2014-15 \\
2. & G2 & KNM 1592 & Early & E2 & Kharif season 2015 \\
3. & G3 & KNM 1598 & Early & E3 & Rabi season 2015-16 \\
4. & G4 & KNM 1600 & Early & & \\
5. & G5 & KNM 1604 & Early & & \\
6. & G6 & KNM 1610 & Early & & \\
7. & G7 & KNM 1616 & Early & & \\
8. & G8 & KNM 1621 & Early & & \\
9. & G9 & KNM 1632 & Medium & & \\
10. & G10 & KNM 1638 & Early & & \\
11. & G11 & KNM 1684 & Early & & \\
12. & G12 & KNM 1685 & Early & & \\
13. & G13 & KNM 1689 & Early & & \\
14. & G14 & KNM 1690 & Early & & \\
15. & G15 & BPT-5204 & Late & & \\
\hline
\end{tabular}

of variance was significant for genotypes, environments and genotypexenvironment $(\mathrm{G} \times \mathrm{E})$ components for yield as well as for days to $50 \%$ flowering indicating the use of GGE biplot analysis in identifying the stable genotypes.

The term "GGE" emphasizes the understanding that $G$ and $G E$ are the two sources of variation that are relevant to genotype variation and must be considered simultaneously for appropriate genotype and the test environment evaluation. GGE biplot analysis has evolved into a comprehensive analysis system whereby most of the questions that may be asked of genotype by environment table can be graphically addressed (Yan et al., 2000; Yan, 2001; Yan and Kang, 2003) and facilitates the comparison of genotypes and their interaction among the environments (Gauch, 2006) for plant breeders, quantitative geneticists and agronomists.

Here the GGE biplot methodology was deployed to investigate the evaluation of environments related to ideal environments, evaluation of genotypes related to ideal genotypes and identification of winning genotypes and their mega environments based on polygon view by which-wonwhere pattern for grain yield and days to $50 \%$ flowering. ANOVA and stability analysis for yield trait and days to flowering was carried out by using the AMMI model and GGE model R-packages 1.5, PB Tools 1.4 version IRRI.

\section{RESULTS AND DISCUSSION}

Dhenotypically stable varieties are usually sought for the commercial production of field crops. The present study was carried out to collect the information on 15 rice genotypes for their stability in three seasons. Pooled analysis of variance revealed that genotypes $(G)$, environments (E) and genotype $\mathrm{x}$ environment (GE) were significantly different among the rice lines tested (Table 2 and 3 ) indicating the differential response of genotypes to the environments and their role in the phenotypic expression for yield and days to $50 \%$ flowering. The highly significant $\mathrm{GxE}$ effects suggest that genotypes may be selected for

Table 2: Analysis of variance over three seasons for yield $\left(\mathrm{kg} \mathrm{ha}^{-1}\right)$

\begin{tabular}{lccc}
\hline Source of variation & \multicolumn{2}{c}{ Yield $\left(\mathrm{kg} \mathrm{ha}^{-1}\right)$} & $\begin{array}{c}\text { \% SS } \\
\text { explained }\end{array}$ \\
\cline { 2 - 3 } & DF & MS & 16.85 \\
Varieties & 14 & $962112.96^{*}$ & 14.87 \\
Environments & 2 & $5943274.55^{*}$ & 52.66 \\
Varietiesx & 28 & $1503415.04^{* * *}$ & \\
Environments & & & \\
PC1 & 15 & $2333273.9^{* * *}$ & \\
PC2 & 13 & $947408.9^{* *}$ & \\
PC3 & 11 & $750238.0^{* *}$ & \\
Error & 45 & 277262.14 & \\
Total & 89 & - & \\
\hline
\end{tabular}

${ }^{*} p<0.05 ;{ }^{* *} p<0.01$; DF: Degrees of freedom; MS: Mean sum of square; SS: Sum of square; PC: Principal component 


\begin{tabular}{|c|c|c|c|}
\hline Source of variation & $\mathrm{DF}$ & MS & $\begin{array}{c}\% \mathrm{SS} \\
\text { explained }\end{array}$ \\
\hline Varieties & 14 & $119.2587^{*}$ & 14.19 \\
\hline Environments & 2 & $4505.7444^{* * *}$ & 76.57 \\
\hline $\begin{array}{l}\text { Varieties } \times \\
\text { Environments }\end{array}$ & 28 & $37.1730^{* * *}$ & 8.84 \\
\hline PC1 & 15 & $135.40271^{* * *}$ & \\
\hline $\mathrm{PC} 2$ & 13 & $40.57675^{* * *}$ & \\
\hline PC3 & 11 & $13.81166^{* *+}$ & \\
\hline Error & 45 & 1.0333 & \\
\hline Total & 89 & - & \\
\hline
\end{tabular}

${ }^{*} p<0.05 ;{ }^{* *} p<0.01$; DF: Degrees of freedom; MS: Mean sum of square; SS: Sum of square; PC: Principal component

adaption to specific environments which is in accordance with the findings of XU et al. (2014). GGE biplot analysis is widely used for the analysis of GGE interaction in multienvironment yield trials (Yan, 2014; Kaplan et al., 2017).

The ANOVA results for grain yield revealed that genotype and environment interaction was the principal source of variation explained $52.66 \%$ and the genotypes were contributed to $16.85 \%$ of the total variation. A low contribution of $14.87 \%$ to the grain yield was observed for environments. These results were superior to those presented by Ponnuswamy et al. (2018) in rice studied by the same model. On the other hand, environment contributed for $76.57 \%$ of the total variation, whereas genotype and genotype and environment interaction recorded low variations $14.19 \%$ and $8.84 \%$, respectively for days to $50 \%$ flowering. High variation of environments for days to $50 \%$ flowering could be due to the low night temperatures $\left(10-15^{\circ} \mathrm{C}\right)$ at nursery to initial tillering stage which results in prolonged duration of varieties during the rabi season 2014-15 (E1) and rabi season 2015-16 (E3). Low night temperatures are usually observed in November, December and January months with the temperature range of $10-15^{\circ} \mathrm{C}$ in Telangana State where the rice nursery and initial tillering stages are exposed. Low temperatures can cause physiological alternations in rice (De Los Reyes et al., 2003).

For grain yield and days to $50 \%$ flowering, all the 15 genotypes significantly differed from each other across the testing seasons indicating thereby substantial variation due to GE. The results also indicated the presence of significant cross-over's. Hence, identification of genotypes based on mean performance would be misleading (Table 4). The
Table 4: Mean grain yield of 15 rice genotypes across three environments

\begin{tabular}{lcccccc}
\hline \multirow{2}{*}{$\begin{array}{l}\text { Genotype } \\
\text { code }\end{array}$} & Designation & \multicolumn{3}{c}{ Yield $\left(\mathrm{kg} \mathrm{ha}^{-1}\right)$} & MY & GR \\
\cline { 3 - 5 } & & E1 & E2 & E3 & & \\
\hline G1 & KNM 1590 & 7610 & 6743 & 7179 & 7177 & 4 \\
G2 & KNM 1592 & 5270 & 6754 & 6896 & 6306 & 14 \\
G3 & KNM 1598 & 7783 & 5861 & 7292 & 6979 & 8 \\
G4 & KNM 1600 & 7563 & 7117 & 7211 & 7297 & 3 \\
G5 & KNM 1604 & 7462 & 5693 & 7181 & 6779 & 10 \\
G6 & KNM 1610 & 7723 & 7213 & 7123 & 7353 & 2 \\
G7 & KNM 1616 & 7726 & 7129 & 7368 & 7407 & 1 \\
G8 & KNM 1621 & 7613 & 6413 & 7305 & 7110 & 6 \\
G9 & KNM 1632 & 8108 & 7082 & 5872 & 7020 & 7 \\
G10 & KNM 1638 & 7660 & 6574 & 7105 & 7113 & 5 \\
G11 & KNM 1684 & 5717 & 4581 & 7909 & 6069 & 15 \\
G12 & KNM 1685 & 7215 & 5253 & 7122 & 6530 & 12 \\
G13 & KNM 1689 & 7737 & 7029 & 5936 & 6901 & 9 \\
G14 & KNM 1690 & 7940 & 7326 & 4831 & 6699 & 11 \\
G15 & BPT-5204 & 7298 & 6502 & 5527 & 6442 & 13 \\
\hline
\end{tabular}

MY: Mean yield $\left(\mathrm{kg} \mathrm{ha}^{-1}\right)$; GR: Genotype by rank

performance of genotypes, instead, should be on the basis of their performance in the respective environments. GGE biplot analysis revealed that high grain yield variability was observed in the first two principal components (PC, s) PC1 and PC2, which explained $63 \%$ and $22 \%$ of the total variation, respectively. Similarly, days to $50 \%$ flowering had a total of $95 \%$ variation explained by PC1 (75\%) and PC2 (20\%). PC 1 values were higher than PC2 for grain yield and days to $50 \%$ flowering explaining a higher contribution of genotype in the total sum of squares.

Among the environments, rabi season 2014-15 (E1) was found to be the most suitable environment for the potential expression of grain yield and the most ideal environment for testing general adoption as it made a small angle with the Average Environment Axis (AEA) and had large PC1 score and small $\mathrm{PC} 2$ score, and representative of all the three environments. This season will help in selecting cultivars that are widely adopted and bear general adoption. It was observed that grain yield was significantly higher in the dry season (rabi) than wet season (kharif) under irrigated rice production in tropical conditions and the variation was observed for the ideotype suitability for different seasons (Bueno and Lafarge, 2017). On the other hand, rabi season 2015-16 (E3) being distant from other testing environments produced the longest environment vector with a large PC2 score. Thus, this environment was regarded as the highly discriminating and desirable testing season for examining 
special adoption for grain yield (Figure 1). The season, rabi 2015-16 (E3) was the most representative and ideal environment for deciphering the general adaptability of the cultivars since it demonstrated a small angle with AEA (Average Environment Axis) for days to 50\% flowering (Figure 2).

An interesting application of GGE biplot is the evaluation

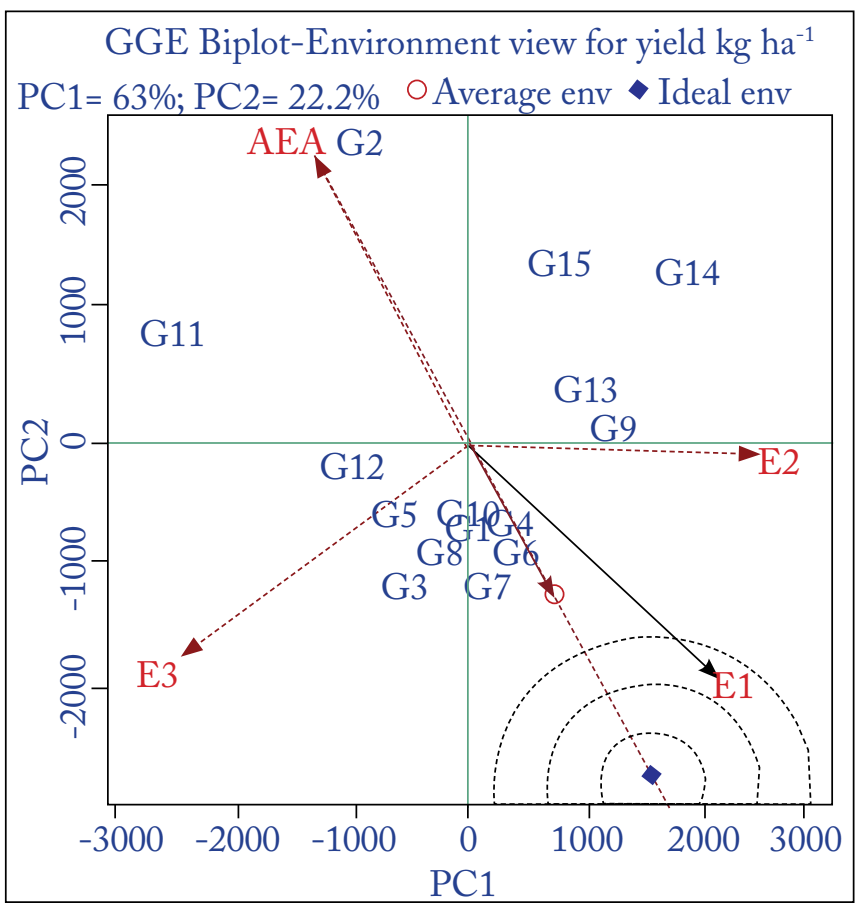

Figure 1: GGE Biplot-Environment view for yield

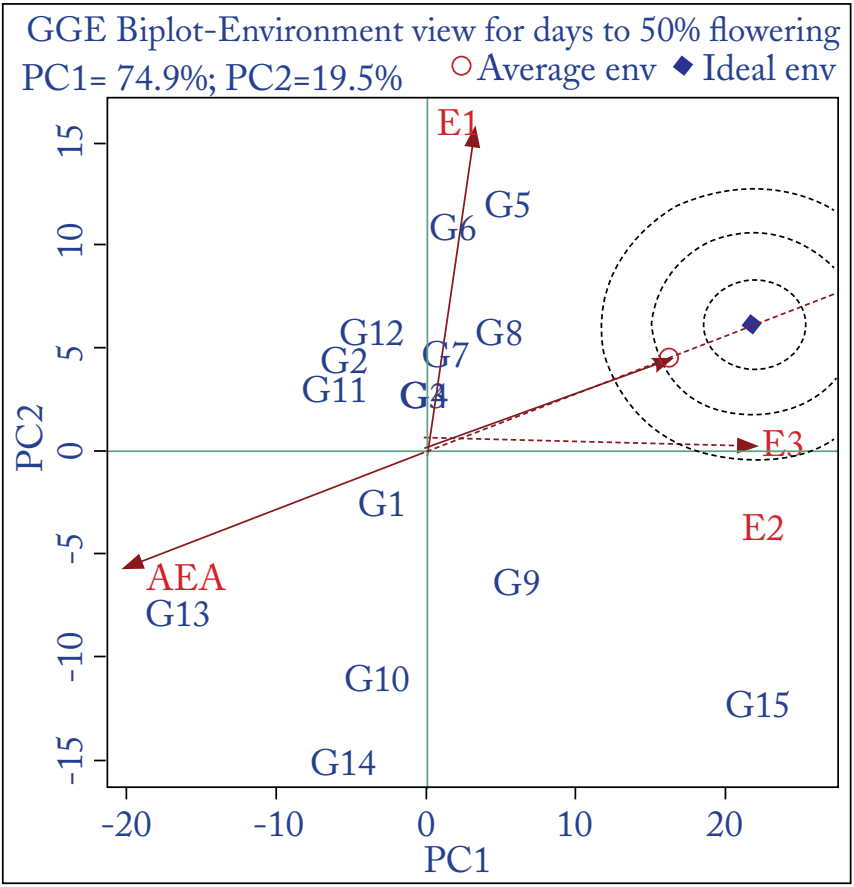

Figure 2: GGE Biplot-Environment view for days to $50 \%$ flowering of a genotype relative to an ideal genotype. Although such an ideal genotype may not exist in reality, it could be used as a reference for genotype evaluation (Mitrovic et al., 2012). An ideal genotype is one with large PC1 scores representing the high yielding ability and small PC2 scores representing high stability (Yan et al., 2000). The concentric circles help to rank the genotypes based on their distances to the ideal genotype, and the genotypes evaluated in multi-environmental trials, shifts in the relative ranking of genotype by environment interactions often occur (Alam et al., 2014; Parihar et al., 2017). Thus, Figure 3 revealed that early genotype G7 (KNM 1616) fell into the center of concentric circles in the positive direction, was nearer to the ideal genotype in terms of high yielding ability and stability, compared with the rest of the genotypes. The second and third most desirable early genotypes would be G6 (KNM 1610) and G4 (KNM 1600), respectively which were near to G7 (KNM 1616). Similar kinds of observations were earlier reported by Poli et al. (2018).

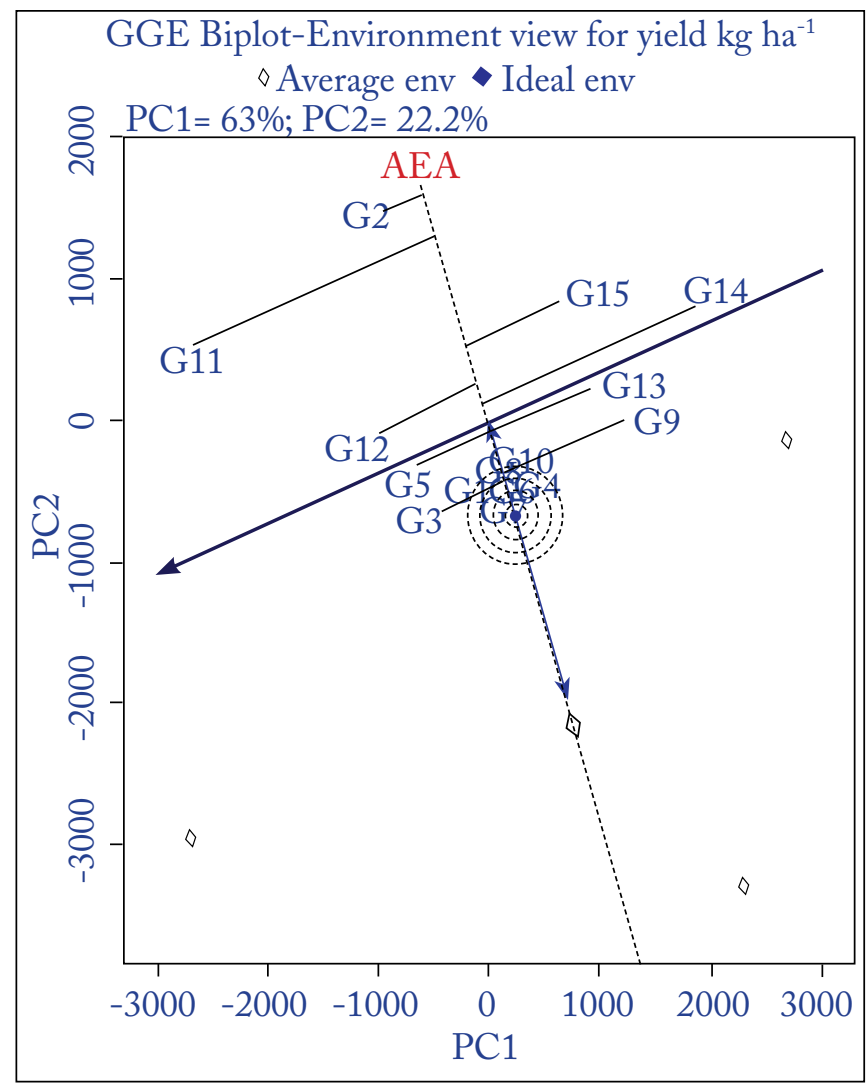

Figure 3: GGE Biplot-Environment view for yield

For days to 50\% flowering, the genotype G15 (BPT 5204) had the highest mean across the environments followed by G9 placed on the center of the concentric circles which represents the medium and longer duration, respectively. On the contrary, genotypes notably G14 (KNM 1690) and G10 (KNM 1638) had lower means for days to $50 \%$ 
flowering across the environments placed in the negative direction represented the stable early duration. The present results are in conformity with the earlier reports and this confirmed that days to $50 \%$ flowering is a stable character (Dushyanth Kumar et al., 2020). However, genotype G13 (KNM 1689) was the least stable genotype and had the lowest mean for days to flowering (Figure 4).

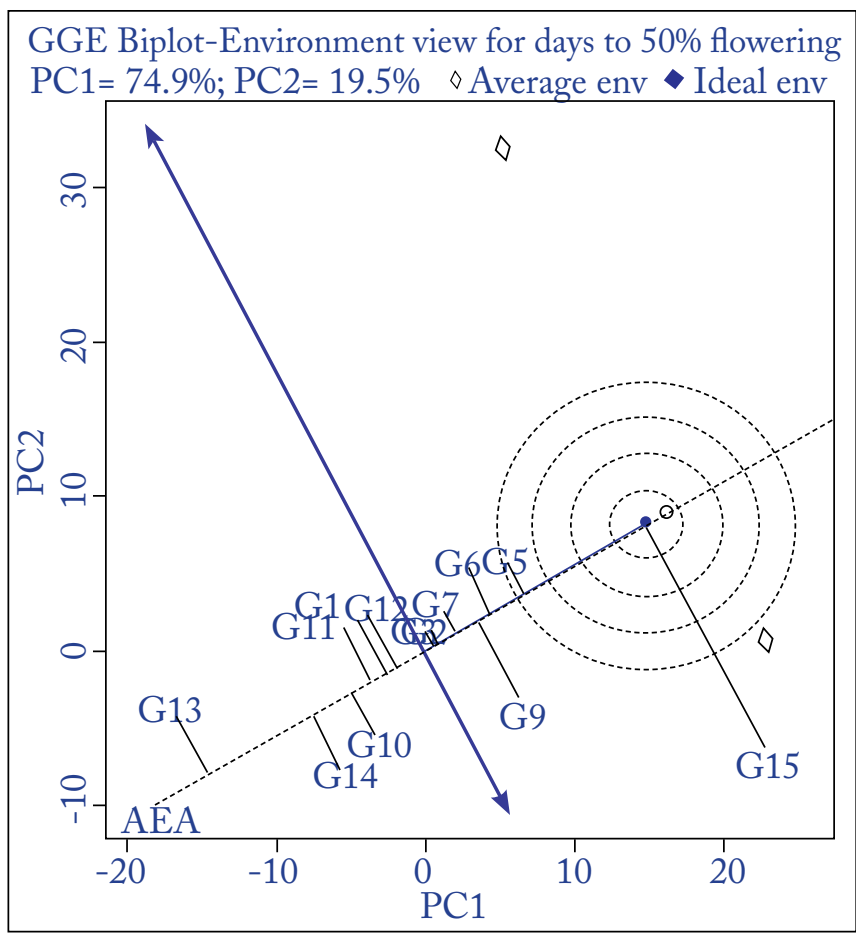

Figure 4: GGE biplot-environment view for days to $50 \%$ flowering

The adaptability of the genotypes across the environments and best-suited genotypes for specific environments was identified based on the GGE biplot polygon viewgraph (Yan and Kang, 2003). One of the most attractive features of a GGE biplot polygon is its ability to show the whichwon-where pattern of a genotype by environment data set (Poli et al., 2018). It divided the biplot into five sections, and three environments fell into two of them as two mega environments for grain yield. Vertex early and medium duration genotypes G14 (KNM 1690) and G9 (KNM 1632) were the winning genotypes in mega environment 1 consisting of kharif season 2015 (E2) and rabi season 2014-15 (E1), respectively. While the early line G11 (KNM 1684) was the winner in mega environment 2 i.e rabi season 2015-16 (E3). Similarly, early genotype G13 (KNM 1689) and late cultivar G15 (BPT 5204) were better in kbarif season 2015 (E2) and rabi season 2014-15 (E1) environments. It concludes that different cultivars should be selected and deployed for each different environment. Similar results were reported by the rice workers (Akter et al., 2015). The other vertex early genotype, G2 (KNM
1592) showed low yield and was poorly adapted to three environments (Figure 5).

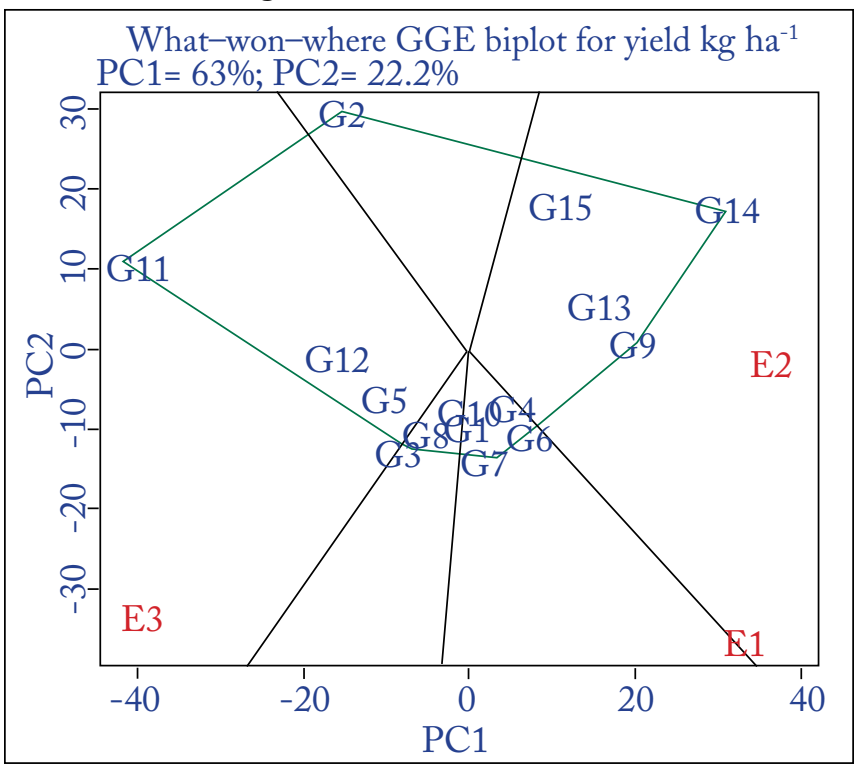

Figure 5: What-won-where GGE biplot for yield

Out of 15 genotypes tested, early line G7 (KNM 1616) was not only high yielding, but also exhibited stable yield across all the seasons. This was evident from Table 4 and Figure 5 where it falls on the vertex of the polygon, and also appears near the biplot origin. Other early genotypes such as G6 (KNM 1610) and G4 (KNM 1600) recorded high yield next to G7 (KNM 1616) with more stability being nearer to biplot origin. These results are in close correspondence with the results reported by Susanto et al. (2015) in rice while studying $\mathrm{G} \times \mathrm{E}$ interaction for $\mathrm{Fe}$ content.

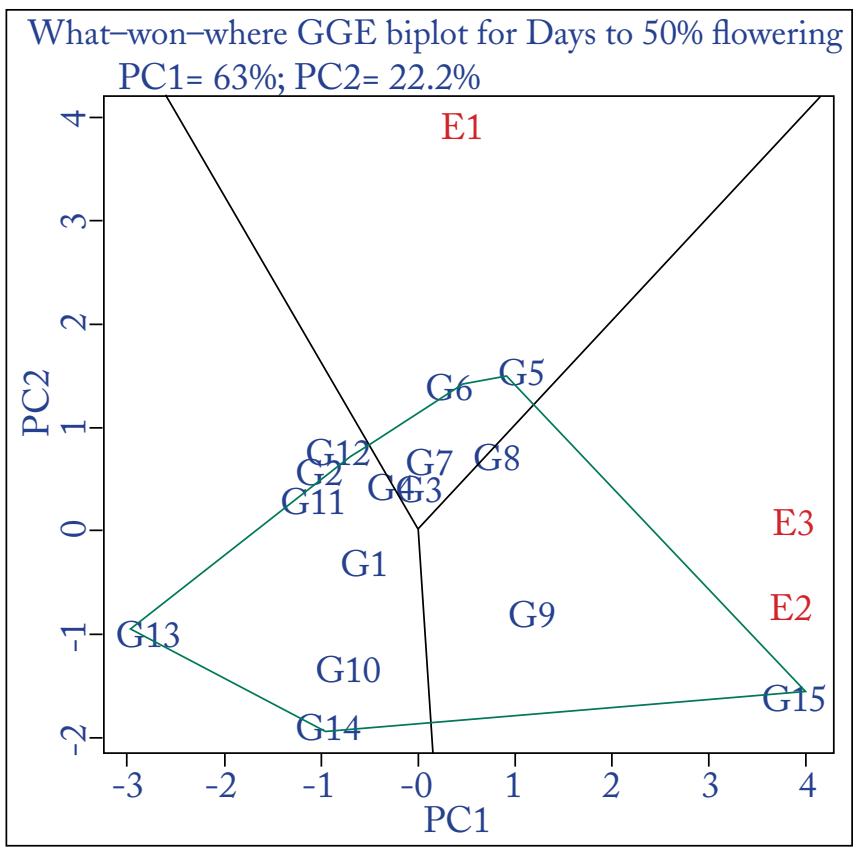

Figure 6: What-Won-Where GGE Biplot for days to $50 \%$ flowering 
With regard to days to 50\% flowering, cultivar G15 (BPT 5204) recorded its lateness in kharif season 2015 (E2) and rabi season 2015-16 (E3) since it was located on the vertex of the polygon falling on E2 and E3 in a positive direction. Similarly, in kharifseason 2015 (E2) and rabi season 201516 (E3) environments, G9 (KNM 1632) was regarded as medium duration variety. In rabi season 2014-15 (E1), G6 (KNM 1610) and G5 (KNM 1604) were late in duration. In comparison with all the lines, G13 (KNM 1689) and G14 (KNM 1690) were found to be early lines (Figure 6).

\section{CONCLUSION}

G enotypes G7 (KNM 1616) and G6 (KNM 1610) are the potential donors for grain yield, and the genotypes G13 (KNM 1689) and G14 (KNM 1690) for earliness improvement. In the current scenario, crossing programme between these genotypes would be a prospective approach with high demand and low inputs for developing short duration high yielding varieties. Winning genotypes G14 (KNM 1690), G11 (KNM 1684) and G13 (KNM 1689) for yield and earliness required further testing in multilocation and multi-environmental trials.

\section{ACKNOWLEDGEMENT}

$\mathrm{T}$ he authors sincerely thank to Regional Agricultural Research Station, Jagtial for providing the support.

\section{REFERENCES}

Ahmadi, J., Mohammadi, A., Najafi Mirak, T., 2012. Targeting promising bread wheat (Triticum aestivum L.) Lines for cold climate growing environments using AMMI and SREG GGE biplot analyses. Journal of Agriculture Science and Technology 4, 645-657.

Akter, A., Jamil Hassan, M., Umma Kulsum, M., Islam, M.R., Hossain, K., Mamunur Rahman, M., 2014. AMMI biplot analysis for stability of grain yield in hybrid rice (Oryza sativa L.). Journal of Rice Research 2,126 .

Aktar, A., Hasan, M.J., Kulsumu., Rahman, M.H., Khatun, M., Islam, M.R., 2015. GGE bi-plot analysis for yield stability in multi-environment trials of promising hybrid rice (Oryza sativa L.). Bangladesh Rice Journal 19(1), 1-8.

Alam, A.K.M., Somta, M.P., Jompuk, C., Chatwachirawong, P., Srinivas, P., 2014. Evaluation of mungbean genotypes based on yield stability and reaction to mungbean yellow mosaic virus disease. The Plant Pathology Journal 30, 261-268. DOI: 10.5423/ ppj.oa.03.2014.0023 PMID:25289012 PMCID: PMC4181119.

Balakrishnan, D., Subrahmanyam, D., Badri, J., Raju, A.K., Rao, V.Y., Kavitha, B., Sukumar, M., Malathi, S.,
Revathi, P., Padmavathi, G., Babu, V.R., Sarla., N., 2016. Genotypexenvironment interactions of yield traits in backcross introgression lines derived from Oryza sativa cv. Swarna/Oryza nivara. Frontiers in Plant Science 7, 1530. doi: 10.3389/fpls.2016.01530.

Bueno, C.S., Lafarge, T., 2017. Maturity groups and growing seasons as key sources of variation to consider within breeding programs for high yielding rice in the tropics. Euphytica 213, 74. https://doi.org/10.1007/ s10681-017-1862-z.

Crossa, J., Cornelius, P.L., Yan, W., 2002. Biplots of linearbilinear models for studying cross over genotypeenvironment interaction. Crop Science 42, 136-144.

De Los Reyes, B.G., Morsy, M., Gibbons, J., Varma, T.S.N., Antoine, W., McGrath, J.M., Halgren, R., Redus, M., 2003. A snapshot of the low temperatures stress transcriptome of developing rice seedling (Oryza sativa L.) via ESTs from subtracted cDNA library. Theoretical and Applied Genetics 107, 1071-1082.

Dewi, K.A., Chozin, A.M., Triwidodo, H., Aswidinnoor, H., 2014. Genotypexenvironment interaction, and stability analysis in lowland rice promising genotypes. International Journal of Agronomy and Agricultural Research 5(5), 74-84.

Dushyantha Kumar, B.M., Purushottam, A.P., Raghavendra, P., Vittal, T., Shubha, K.N., Madhuri, R., 2020. Genotype environment interaction and stabilty for yield and its components in advanced breeding lines of red rice (Oryza sativa L.). Bangladesh Journal of Botany 49(3), 425-435.

Ebdon, J.S., Gauch, H.G., 2002. Additive main effect and multiplicative interaction analysis of national turf grass performance trials: II. Cultivar recommendations. Crop Science 42, 497-506.

Gauch, H.G., 2006. Statistical analysis of yield trials by AMMI and GGE. Crop Science 46, 1488-1500.

Goncalves, G.M.C., Gomes, R.L.F., Lopes, A.C.A., Vieira, P.F.M., 2020. Adaptability and yield stability of soyabean genotypes by REML/BLUP and GGE biplot. Crop Breeding and Applied Biotechnology 20(2), 1-9.

Jeberson, M.S., Kant, L., Kishore, N., Rana, V., Walia, D.P., Singh D., 2017. AMMI and GGE biplot analysis of yield stability and adaptability of elite genotypes of bread wheat (Triticum aestivum L.) for Northern hill zone of India. International Journal of Bio-resource and Stress Management 8(5), 635-641.

Kaplan, M., Kokten, K., Akcura, M., 2017. Assessment of genotypextraitxenvironment interactions of silage maize genotypes through GGE biplot. Chilean Journal of Agricultural Research 77, 212-217.

Kesh, H., Kharb, R., Ram, K., Munjal, R., Kaushik, P., Kumar, D., 2021. Adaptability and AMMI biplot 
analysis for yield and agronomical traits in scented rice genotypes under diverse production environments. Indian Journal of Traditional Knowledge 20(2), 550-562.

Khush, G.S., 2005. What will take to feed 5.0 billion rice consumers in 2030. Plant Molecular Biology 59, 1-6.

Mitrovic, B., Stanisavljevi, D., Treski, S., Stojakovic, M., Ivonic, M., Bekabac, G., Rajkovic, M., 2012. Evaluation of experimental maize hybrids tested in multi-location trials using AMMI and GGE biplot analysis. Turkish Journal of Field Crops 17(1), 35-40.

Nili, A., Rabiei, B., Allahgholipour, M., Ebadi, A.A., 2017. Assessing molecular diversity and genetic relationships among rice (Oryza sativa L.) varieties. Cereal Research Communications 7, 33-50. https:// doi.org/10.22124/c.2017.2427.

Oladosu, Y., Rafii, M.Y., Abdullah, N., Magaji, U., Miah, G., Hussin, G., Ramli, A., 2017. Genotypex Environment interaction and stability analyses of yield and yield components of established and mutant rice genotypes tested in multiple locations in Malaysia. Acta Agriculturae Scandinavica, Section B-Soil \& Plant Science 7, 590-606.

Parihar, A.K., Basandrai, A.K., Sirari, A., Dinakaran, D., Singh, D., Kannan, K., Kushawaha, P.S., Adinarayan, M., Akram, M., Latha, T.K.S., Paranidharan, V., Gupta, S., 2017. Assessment of mungbean genotypes for durable resistance to yellow mosaic disease: genotypexenvironment interaction. Plant Breeding 136, 94-100.

Poli, Y., Balakrishnan, D., Desiraju, S., Panigrahy, M., Voleti, S.R., Mangrauthia, S.K., Neelamraju, S., 2018. genotype $\times$ environment interactions of nagina22 rice mutants for yield traits under low phosphorus, water limited and normal irrigated conditions. Scientific Reports 8(1), 15530. DOI: 10.1038/s41598-01833812-1. PMID: 30341356; PMCID: PMC6195568.

Ponnuswamy, R., Rathore, A., Vemula, A., Das, R.R., Singh, A.K., Balakrishnan, D., 2018. Analysis of multi-location data of hybrids rice trials reveals complex genotype by environment interaction. Cereal Research Communications 46(1), 146-157.

Rao, P.V.R., Divyasri, S., Bhanu K.V., Kumari, P.N., Karteek, J., Rani, M.G., Kumar, B.N.V.S.R.R., Chamundeswari, N., Mohan vishnuvardhan, K., Roja, V., Satyanarayana, P.V., Reddy, A.V., 2016. Molecular characterization and diversity analysis for leaf folder resistance in rice using microsatellite markers. International Journal of Economic Plants 3(4), 128-136.

Rasul, G., Glover, K.D., Krishnan, G.P., Padmanaban, G., Jixiang, W., Berzonsky, W.A., Fofana, B., 2017. Genetic analyses using GGE model and a mixed linear model approach, and stability analyses using AMMI bi-plot for late-maturity alpha-amylase activity in bread wheat genotypes. Genetica 145(3), 259-268. https://doi.org/10.1007/s10709-017-9962-1.

Sharifi, P., Aminpanah, H., Erfani, R., Mohaddesi, A., Abbasian, A., 2017. Evaluation of Genotypexenvironment interaction in rice based on AMMI model in Iran. Rice Science 24(3), 173-180. Suman, K., Neeraja, C.N., Madhubabu, P., Rathod, S., Bej, S., Jadhav, K.P., Kumar, J.A., Chaitanya, U., Pawar, S.C., Rani, S.H., Subbarao, L.V., Voleti, S.R., 2021. Identification of promising RILs for high grain zinc through genotypexenvironment analysis and stable grain zinc QTL using SSRs and SNPs in rice (Oryza sativa L.). Frontiers in Plant Science 12, 587482. doi: 10.3389/fpls.2021.587482. PMID: 33679823; PMCID: PMC7930840.

Susanto, U., Rohaeni, W.R., Johnson, S.B., Jamil, A., 2015. GGE biplot analysis for genotypexenvironment interaction on yield trait of high Fe content rice genotypes in Indonesian irrigated environments. Agriveta 37(3), 265-275.

Worku, M., Makumbi, D., Beyene, Y., Das, B., Mugo, S., Pixley, K., Banziger, M., Owino, F., Olsen, M., Asea, G., Prasanna, B.M., 2016. Grain yield performance and flowering synchrony of CIMMYT's tropical maize (Zea mays L.) parental inbred lines and single crosses. Euphytica 211, 395. doi: 10.1007/ s10681-016-1758-3.

XU, F.F., Tang, F.F., Shao, Y.F., Chen, Y.L., Tong, C., Bao, J.S., 2014. Genotypexenvironment interaction for agronomic traits of rice revealed by association mapping. Rice Science 21(3), 133-141.

Yan, W., 2001. GGE biplot : A windows application for graphical analysis of multi-environment trial data and other types of two-way data. Agronomy Journal 93(5), 1111-1118.

Yan, W., 2014. Crop variety trials: Data management and analysis. John Wiley and Sons., New York, USA, 349. ISBN:9781118688571, DOI:10.1002/9781118688571.

Yan, W., Hunt, L.A., Sheng, Q. Szlavnics, Z., 2000. Cultivar evaluation and mega environment investigation based on the GGE biplot. Crop Science 40, 597-605.

Yan, W., Kang, M.S., 2003. GGE biplot analysis: a graphical tool for breeders, geneticists and agronomists. CRC Press LLC, Boca Raton, Florida, 271. ISBN: 0849313384, URL : http://www.crcpress.com Yan, W., Kang, M.S., Ma, B.L., Woods, S., Cornelius, P.L., 2007. GGE biplot vs. AMMI analysis of genotype-by-environment data. Crop Science 47, 643-653. 